\title{
A Quick Method for Estimating the Stage of the Sunspot Cycle
}

\author{
W. B. Chadwick \\ Contribution from Central Radio Propagation Laboratory, National Bureau of Standards, Boulder, Colo.
}

(Received June 22, 1961)

\begin{abstract}
A method, based on the maximum median hourly value of $f_{0} F_{2}$ month-by-month as observed at Washington, D.C., is given for predicting a smoothed annual sunspot number immediately at the close of a given month, centered on the month in question. Regression equations and standard errors are given. It should be a useful supplement to the MeNishLincoln method of prediction of sunspot numbers, particularly during the first two years of the rising part of a sunspot cycle. It is capable of use with the observations from any ionosphere sounding station operated in a consistent manner over a period of years, preferably during at least two solar cycles.
\end{abstract}

\section{Introduction}

One of the widely accepted methods used in the prediction of sunspot numbers for use in radio frequency predictions is the McNish-Lincoln method [1949]. This method involves the use of smoothed annual sunspot numbers corrected by departures one year earlier than the time in question. It predicts month by month the "best" prediction for 1 year ahead.

The use of a 12-month running average suffers of course from the fact that to obtain the sunspot number applicable to a certain month, 6 months in the future must be observed. When, however, the authors extended the technique to the prediction of 3-month mean sunspot numbers, lower overall reliability resulted. The method outlined here has the advantage that, immediately upon the completion of a month, a prediction of the 12 -month running average sunspot number centered on that month can be made. Of considerable importance is the fact that the rms deviation of prediction would seem to be of about the same order of magnitude as those given in a second paper [McNish and Lincoln, 1954] in which the authors examined the reliability of their method of prediction and applied it to cycle 18.

In the proposed method, the highest monthly median value of $f_{0} F_{2}$ for any hour, as observed at Washington, D.C., is used, in a set of 12 regression equations, one for each month, to obtain an estimate of the 12-month running average sunspot number for the month that has just ended. It is believed that this choice of maximum $f_{0} F_{2}$, rather than $f_{0} F_{2}$ for a fixed time of day, is of aid in minimizing seasonal effects.

The idea of using $f_{0} F_{2}$ as a measure of solar activity is not new, but the methods so far proposed have been more elaborate, involving for instance such things as 5-hourly averages centered on noon, and averaging of results from several stations [Phillips, 1947; Minnis, 1955]. Also much work has been done and is continuing on other possible indices [Kundu and Denisse, 1958; Minnis and Bazzard, 1959]. The fact that a reasonable answer can be obtained to the problem of predicting solar activity by the simple method outlined here, gives reason for hope that the much more elaborate methods presently under study will eventually result in a highly satisfactory index obtained from some combination of physical quantities. At the same time, it is distinctly worthwhile to have some way of connecting future ionospheric indices with the long timeseries of sunspot numbers now available, on which so many relationships have previously been based.

The method of this paper is intended to show what can be done almost immediately using data from but one ionosphere station (Washington) which has been operated in a consistent fashion over a long period of time. The initial impetus for this study was the sudden drop in solar activity in January 1961 as represented by the provisional Zürich monthly sunspot number of 53.5, together with the desire to investigate what this sudden drop might mean in terms of future predictions of critical frequencies.

\section{Correlation Coefficients}

Various results are given in table 1 . It will be noted that, in general, the coefficients in column A exceed those in column B, and those in column $\mathrm{E}$ exceed those in column D. (However, these observed tendencies by themselves are not statistically significant.) Column $\mathrm{C}$ is filled out only for January and May, the months for which the highest and lowest coefficients were obtained in column A. The omission of numbers for the maximum period 1957 to 1959 (col. C) and the reduction of high numbers in this period (col. E) gave correlations which, when taken with those in columns $\mathrm{A}$ and $\mathrm{D}$, form an interesting series of coefficients for these months. 
TABLE 1. Correlation coefficients, maximum hourly median $f_{0} F_{2}$ (Washington) versus Zürich sunspot number for various periods; $A, C, D$, versus 12-month running average sunspot number centered on the month in question; $B$, versus monthly sunspot number; $E$, same as $D$, but with sunspot numbers $>150$ used as 150

\begin{tabular}{|c|c|c|c|c|c|}
\hline & A & B & C & D & $\mathrm{E}$ \\
\hline & $1945-1960$ & $1945-1960$ & $1941-1956,1960$ & $1941-1960$ & $1941-1960$ \\
\hline $\begin{array}{l}\text { Jan } \\
\text { Feb } \\
\text { Mar } \\
\text { Apr } \\
\text { May } \\
\text { June }\end{array}$ & $\begin{array}{l}0.989 \\
.98 \\
.97 \\
.93 \\
.88 \\
.92\end{array}$ & $\begin{array}{l}0.97 \\
.94 \\
.97 \\
.92 \\
.91 \\
.89\end{array}$ & 0.985 & $\begin{array}{l}0.989 \\
.98 \\
.96 \\
.94 \\
.90 \\
.93\end{array}$ & $\begin{array}{l}0.975 \\
.98 \\
.97 \\
.97 \\
.93 \\
.96\end{array}$ \\
\hline $\begin{array}{l}\text { July } \\
\text { Aug } \\
\text { Sep-... } \\
\text { Oct-. } \\
\text { Nov } \\
\text { Dec }\end{array}$ & $\begin{array}{l}.92 \\
.92 \\
.95 \\
.96 \\
.98 \\
.97\end{array}$ & $\begin{array}{l}.93 \\
.89 \\
.95 \\
.93 \\
.94 \\
.94\end{array}$ & 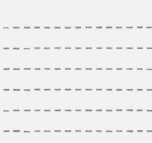 & $\begin{array}{l}.94 \\
.93 \\
.96 \\
.97 \\
.98 \\
.98\end{array}$ & $\begin{array}{l}.96 \\
.95 \\
.98 \\
.97 \\
.98 \\
.98\end{array}$ \\
\hline
\end{tabular}

The use of a value of 150 for all running average sunspot numbers over 150, produced an equal or better correlation, except for January. This is in agreement with previously noted results [Bennington, 1958; Ostrow, 1959] and with CRPL predictions practice during the recent maximum. ${ }^{1}$ In January, at the recent maximum period, increased solar activity did seem to have a marked effect in raising the criticals at Washington to a very high value in the middle of the day, higher than CRPL predictions based on sunspot number 150 . Also it

\footnotetext{
1 CRPL Series D, Basic Radio Propagation Predictions, U.S. Government Printing Office, Washington 25, D.C.. Nos. 146-173. Predictions for Jan. 1957Apr. 1959, issued Oct. 1956-Jan.1959.
}

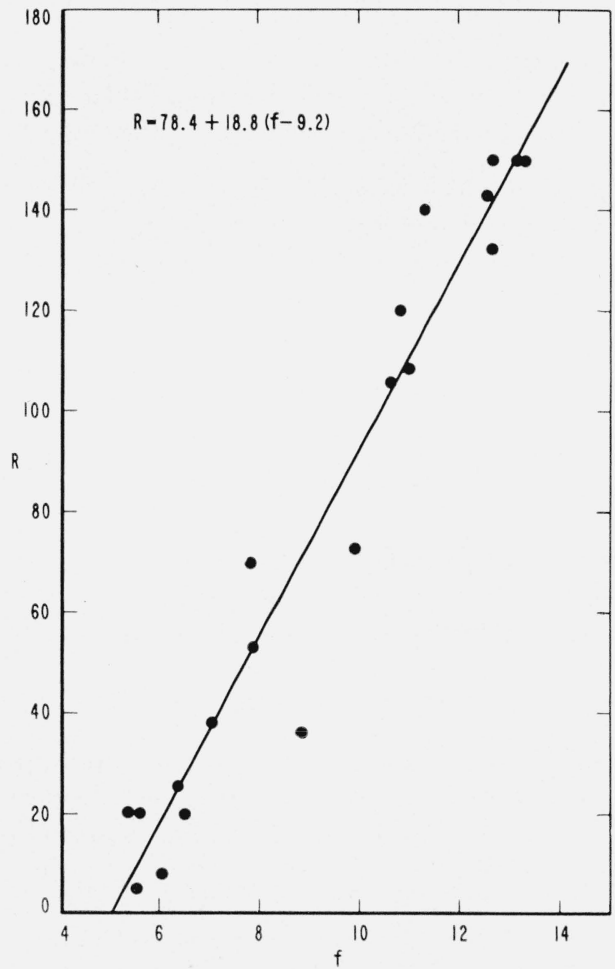

FIGURE 1. Scatter of points and regression line for March (tables 1 and 2, col. E). will be noted that correlations are somewhat higher for the winter months, a not unexpected result, as it has long been noted at Washington that the range of variation in $f_{0} F_{2}$ over the solar cycle, is much greater for winter months than for summer months. While it might be argued that the apparent seasonal effect was due to the way the sunspot numbers happened to fall, e.g., if there had been four numbers for January around 200 and none for June greater than 150 , it should be remarked that during. the recent maximum (1956 to 1959) each month had one 12 -month running average sunspot number $>187$, and each month had three $>150$. Column $\mathrm{B}$ is included to show that correlations can be very high between monthly sunspot numbers and critical frequency. Figure 1 illustrates the relationship between $f$ and $R$ leading to the correlation coefficient 0.97 in column E, table 1, for March.

\section{Regression Equations}

Table 2 gives the linear regression equations for each month of the year, based on the coefficients in column $\mathrm{E}$ of table 1. In addition, equations are given for October through February using the coefficients of column D, which are greater than or equal to the corresponding coefficients in column $\mathrm{E}$.

TABLE 2. Regression equations; $R=12$ - month running average sunspot number, $f=$ maximum hourly median $f_{0} F_{2}(\mathrm{Mc} / \mathrm{s})$, columns D, E correspond to D, E in table 1

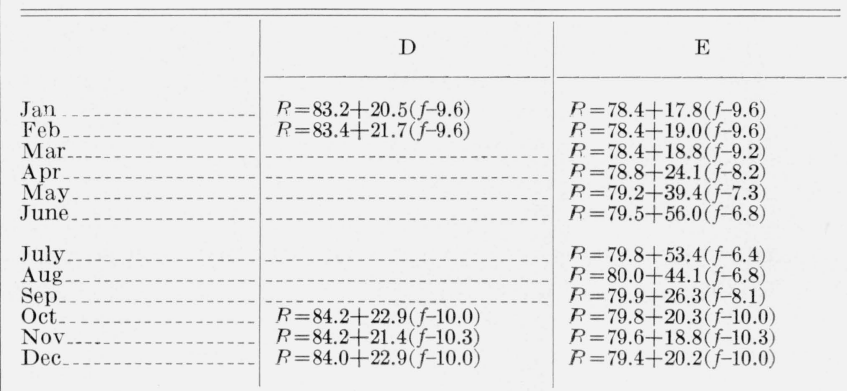

\section{Standard Error of an Estimated Sunspot Number}

Table 3 gives the low and high values of $f$ (maximum hourly median $f_{0} F_{2}$ in $\mathrm{Mc} / \mathrm{s}$ ) month by month over the 20 -year period 1941 to 1960 , as well as the means, which, of course, are repeated from table 2 . Table 4 gives the standard error of an estimated sunspot number, $R$, for each value of $f$ given in table 3. These are computed from the formula

$$
s_{R(\text { est. })}=s_{R \cdot f} \sqrt{1+\frac{1}{n}+\frac{(f-\bar{f})^{2}}{\sum\left(f_{i}-\bar{f}\right)^{2}}} \text { [Snedecor, 1946] }
$$

where $n$ is the number of observed pairs $\left(f_{i}, R_{i}\right)$, $\bar{f}=\sum f_{i} / n, s_{R \cdot f}$ is the sample standard deviation about the regression line, and $f$ is the predicting value of $f_{0} F_{2}$ as before. They may be compared with the 
TABLE 3. Range of values of $f(M c / s)$, Washington, 1941-1960

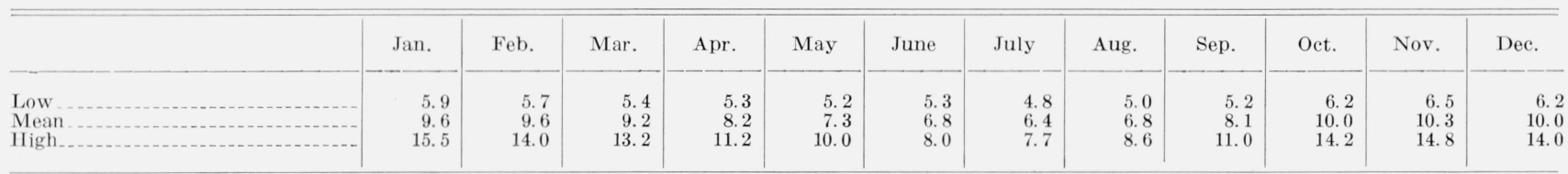

TABLE 4. Standard error of an estimated $R$ for various values of $f$ (see table 3 )

\begin{tabular}{|c|c|c|c|c|c|c|c|c|c|c|c|c|c|c|c|c|c|}
\hline & \multirow{2}{*}{$\begin{array}{l}\text { Jan. } \\
\text { Col. D, } \\
\text { table } 2\end{array}$} & \multirow{2}{*}{$\begin{array}{l}\text { Jan. } \\
\text { Col. E, } \\
\text { table } 2\end{array}$} & \multirow{2}{*}{$\begin{array}{l}\text { Feb. } \\
\text { Col. D, } \\
\text { table } 2\end{array}$} & \multirow{2}{*}{$\begin{array}{l}\text { Feb. } \\
\text { Col. E, } \\
\text { table } 2\end{array}$} & \multicolumn{7}{|c|}{ Col. E, table 2} & \multirow{2}{*}{$\begin{array}{l}\text { Oct. } \\
\text { Col. D, } \\
\text { table } 2\end{array}$} & \multirow{2}{*}{$\begin{array}{l}\text { Oct. } \\
\text { Col. E, } \\
\text { table } 2\end{array}$} & \multirow{2}{*}{$\begin{array}{l}\text { Nov. } \\
\text { Col. D, } \\
\text { table } 2\end{array}$} & \multirow{2}{*}{$\begin{array}{l}\text { Nov. } \\
\text { Col. E, } \\
\text { table } 2\end{array}$} & \multirow{2}{*}{$\begin{array}{l}\text { Dec. } \\
\text { Col. D, } \\
\text { table } 2\end{array}$} & \multirow{2}{*}{$\begin{array}{l}\text { Dec. } \\
\text { Col. E, } \\
\text { table } 2\end{array}$} \\
\hline & & & & & Mar. & Apr. & May & June & July & Aug. & Sep. & & & & & & \\
\hline $\begin{array}{l}\text { For low } f \\
\text { For mean } f \\
\text { For high } f\end{array}$ & $\begin{array}{l}10.9 \\
10.6 \\
11.7\end{array}$ & $\begin{array}{l}13.3 \\
12.8 \\
14.1\end{array}$ & $\begin{array}{l}13.7 \\
13.1 \\
13.9\end{array}$ & $\begin{array}{l}11.1 \\
10.6 \\
11.3\end{array}$ & $\begin{array}{l}14.3 \\
13.8 \\
14.4\end{array}$ & $\begin{array}{l}16.2 \\
15.5 \\
16.2\end{array}$ & $\begin{array}{l}23.5 \\
22.1 \\
23.8\end{array}$ & $\begin{array}{l}18.1 \\
17.1 \\
17.7\end{array}$ & $\begin{array}{l}17.8 \\
16.8 \\
17.5\end{array}$ & $\begin{array}{l}19.3 \\
18.3 \\
19.3\end{array}$ & $\begin{array}{l}13.0 \\
12.4 \\
13.0\end{array}$ & $\begin{array}{l}17.8 \\
17.0 \\
18.0\end{array}$ & $\begin{array}{l}16.1 \\
15.4 \\
16.3\end{array}$ & $\begin{array}{l}12.8 \\
12.3 \\
13.0\end{array}$ & $\begin{array}{l}12.4 \\
11.9 \\
12.6\end{array}$ & $\begin{array}{l}14.5 \\
13.8 \\
14.6\end{array}$ & $\begin{array}{l}12 . \\
11 . \\
12 .\end{array}$ \\
\hline
\end{tabular}

rms deviation of prediction given in table 1 of McNish and Lincoln [1954], in which the deviations range from 7.0 to 19.2 . Although these are of the same order of magnitude, it must be remembered that the McNish-Lincoln formulas were obtained using data from 10 solar cycles, whereas the standard errors of this paper were calculated using less than 2 cycles. Essentially the sunspot numbers used in the McNish-Lincoln method form a series of numbers spaced one solar cycle or about 11 years apart, whereas in this method the sunspot numbers are spaced 1 year apart.

\section{Results and Conclusions}

Since this paper was begun, values of maximum hourly median $f_{0} F_{2}$ at Washington have been received for January through May 1961. These are listed in table 5 , together with the values of 12 -month running average Zürich sunspot number estimated by the method of this paper, and those predicted by the McNish-Lincoln method. It must be remembered, of course, that the latter predictions were made, for the corresponding months, 6 months earlier than the predictions using the critical frequencies at Washington.

At the time of final version of this paper (June $5,1961)$ the provisional 12 -month running average Zürich sunspot number, centered on December 1, 1960, had dropped to 84.3 . At the average rate of decline for the past 4 months, the number centered on the middle of January 1961 would be 76.7, compared with the predicted values 75.0 and 97.4 of table 5 .
TABLE 5. Values of $f$ at Washington, estimated values of $R$, predicted values of $R$ by McNish-Lincoln method, Jan.May 1961

\begin{tabular}{c|c|c|c}
\hline \hline \multirow{2}{*}{1961} & $f(\mathrm{Mc} / \mathrm{s})$ & $R$ (Est.) & $R$ (Pred., McNish-Lincoln) \\
\cline { 1 - 2 } & & & \\
\cline { 1 - 2 } Jan & 9.2 & a 75.0 & 97.4 \\
Feb & 8.6 & 59.4 & 93.8 \\
Apr & 8.6 & 67.1 & 90.2 \\
May & 7.4 & 59.5 & 88.5 \\
& 6.8 & 59.5 & 86.2 \\
\hline
\end{tabular}

a From table 2, col. D; all others from table 2, col. E.

A quick method of this type should prove especially valuable during the first 2 years of the rising part of a solar cycle, to help give an early indication of the level and timing of the coming maximum.

It would of course be desirable to augment the sample size for estimating the regression equations of table 2 as more years of data become available, in particular the years 1961 and 1962, thus completing a 22-year period. Also it should be noted that a similar thing could be done for any ionosphere sounding station having a long run of well-taken data. Thus delays in waiting for information from other parts of the world could be avoided.

An indication of the degree of accuracy at certain other locations may be obtained from table 6. Estimated values of $R$ for January 1961 from the regression equations given in this table, are, for the respective stations, $70.6,75.7,81.4$, and 84.5 .

It is suggested that adequate results might be obtained from two locations, one in each hemisphere, at about the geomagnetic latitude of Washington, each station to cover its own winter months. For the

TABLE 6. Correlation coefficients, regression equations, standard errors for four stations, 1945 to 1960, Jan., July

\begin{tabular}{|c|c|c|c|c|c|c|c|}
\hline \multirow{2}{*}{ Station } & \multirow{2}{*}{$\begin{array}{l}\text { Geomag. } \\
\text { lat. }\end{array}$} & \multicolumn{2}{|c|}{ Corr. coeff. } & \multicolumn{2}{|c|}{ Regression equations } & \multicolumn{2}{|c|}{ b Standard errors } \\
\hline & & Jan. & July & Jan. & July & Jan. & July \\
\hline $\begin{array}{l}\text { Fairbanks } \\
\text { Washington } \\
\text { Christchurch } \\
\text { Huancayo }\end{array}$ & $\begin{aligned} 64^{\circ} & \mathrm{N} \\
50^{\circ} & \mathrm{N} \\
48^{\circ} & \mathrm{S} \\
1^{\circ} & \mathrm{S}\end{aligned}$ & $\begin{array}{r}0.98 \\
.99 \\
.94 \\
.97\end{array}$ & $\begin{array}{r}0.91 \\
.92 \\
\mathrm{a} .96 \\
.96\end{array}$ & $\begin{array}{l}R=96.0+21.2(f-8.3) \\
R=96.0+20.3(f-10.2) \\
R=96.0+48.7(f-7.7) \\
R=96.0+28.7(f-11.2)\end{array}$ & $\begin{aligned} R & =98.5+64.4(f-5.7) \\
R & =98.5+60.7(f-6.7) \\
\mathrm{a} & =102.4+22.8(f-8.9) \\
R & =98.5+35.7(f-8.9)\end{aligned}$ & $\begin{array}{r}13.9 \\
9.5 \\
22.2 \\
15.8\end{array}$ & $\begin{array}{r}27.7 \\
24.3 \\
\mathrm{a} 18.9 \\
17.3\end{array}$ \\
\hline
\end{tabular}

a 15 years; data missing for July 1955 .

b Standard error of an estimated $R$ for mean $f$. 
equinoxes, possibly the station with the longer time series would be used.

Finally, the presentation of two sets of equations in table 2 (columns D and $\mathrm{E}$ ) is intended to be illustrative of two ways of obtaining the result. One should not necessarily switch from one type of equation to another, because in small samples such as these the reversal in size of correlation coefficients or other criteria could happen frequently and not be significant.

\section{References}

Bennington, T. W., Apparent saturation in F2 Layer, Wireless World 64, No. 10, 472-473 (Oct. 1958).

Kundu, M. R., and J. F. Denisse, Solar radiation on decimeter waves as an index for ionospheric studies, JATP 13, Nos. 1/2, 176-178 (July-Dec. 1958).
Minnis, C. M., A new index of solar activity based on ionospheric measurements, JATP , No. 6, 310-321 (Dec. 1955).

Minnis, C. M., and G. H. Bazzard, Some indices of solar activity based on ionospheric and radio noise measurements, JATP 14, Nos. 3/4, 213-228 (Mar.-Apr. 1959).

MeNish, A. G., and J. V. Lincoln, Prediction of sunspot numbers, Trans. AGU 30, No. 5, 673-685 (Oct. 1949).

MeNish, A. G., and J. V. Lincoln, Predicition of the present sunspot cycle, Trans. AGU 35, No. 5, 709-710 (Oct. 1954).

Ostrow, S. M., Variation of critical frequency with sunspot number, Paper presented at Spring Meeting of URSI, Washington, 1959.

Phillips, M. L.. The ionosphere as a measure of solar activity, Terrestrial Magnetism and Atmospheric Elect. 52, No. 3, 321-332 (Sept. 1947).

Snedecor, G. W., Statistical Methods, The Iowa State College Press, 137 (4th ed., 1946).

(Paper 65D6-166) 